\title{
Clinical toxicology of 'magic mushroom' ingestion
}

\author{
N. R. PEDEN \\ M.A., M.R.C.P. \\ K. E. C. Macaulay \\ M.B., Ch.B.
}

\author{
ANN F. BisSETT \\ M.A., S.R.N. \\ J. Crooks \\ M.D., F.R.C.P.
}

\author{
A. J. PELOSI* \\ M.B., M.R.C.P.
}

Department of Therapeutics, University of Dundee, and *Department of Medicine, Perth Royal Infirmary

\begin{abstract}
Summary
The clinical features are reported in 27 cases of 'magic mushroom' ingestion. Mydriasis and hyperreflexia were common as were disorders of perception and affect. Psilocybe semilanceata appears to have been the species of fungus involved.
\end{abstract}

\section{Introduction}

Hallucinogenic mushrooms have been used for magico-religious purposes by the Indians of Mexico for many centuries (Wasson, 1959) but the active constituents, psilocybin and psilocin were not identified until 1958 (Hofman et al., 1958). These compounds were subsequently found in the British species Psilocybe semilanceata (Benedict, Tyler and Watling, 1967; Mantle and Waight, 1969) but, despite widespread use of psilocybin mushrooms for 'recreational purposes' elsewhere (Pollock, 1975), it was not until 1978 that such use was described in Britain (Hyde et al., 1978) from 3 patients from Manchester. There have since been further case reports form Glasgow (Mills, Lesinkas and Watkinson, 1979) and Aberdeen (Cooles, 1980) and the subject has also received comment in a national newspaper (The Observer, 1980). Two handbooks for would-be users of these mushrooms have recently been published (Cooper, 1979; Release Collective, 1979).

Ingestion of these so-called 'magic mushrooms' has been popular amongst teenagers in the Tayside region in the past 2 Autumns and the authors feel that a description of the clinical features will be useful for clinicians who may see such patients for acute medical or psychiatric assessment.

\section{Patients}

Twenty-seven patients presented to hospital following the ingestion of magic mushrooms in the months of September and October of 1979 and 1980. The authors personally admitted or subsequently interviewed 8 of the patients and the case records of all the patients have been reviewed. The mean age was 16.3 years (range $12-24$ years) and 10 were school children. Seven patients were self-referrals. Of the remainder, 12 were brought to hospital by concerned parents, 5 by friends, 2 by the police and one had telephoned the Samaritans.

\section{Mushrooms and mode of ingestion}

The authors have identified $P$. semilanceata growing on sites described by patients and also in gastric contents aspirated from patients. Illustrated descriptions of the fungus have been published (Watling, 1973a; Cooper, 1979).

The number of mushrooms ingested varied from 'a handful' to 100, (mean 56 in those patients who quantified it). Eighteen patients ate the mushrooms raw while in 6 cases the mushrooms were brewed in boiling water and the liquor consumed. Two patients ate dried mushrooms and one a mushroom stew.

\section{Clinical features}

Tachycardia of $\geqslant 100$ beats per minute (b/min) was noted in 10 patients while only one was significantly hypertensive (BP $180 / 110 \mathrm{mmHg}$ ). Pupils were dilated (but reacting to light) in 20 of the 23 patients in whom pupil size was noted. Deep tendon reflexes were brisk in 12 of 18 patients from whom this information was recorded. Three patients exhibited facial flushing, 3 suffered transient abdominal pain and nausea, one patient was vomiting on admission and one was incontinent of urine.

Alterations in perception occurred in 23 patients 
and chiefly affected vision. Colours appeared to be particularly vivid and kaleidoscopic phenomena and flashes of coloured light were described. Facial appearance received special comment with faces appearing to change shape and colour and also to stare at the patient. Fully formed visual hallucinations of people occurred in 4 patients and in one case these were interpreted as being Martians.

Two patients noted that perception of sound was heightened while 2 suffered auditory hallucinations. Body image perception was affected in 4 patients who complained of apparent swelling of bodily parts including the tongue, while 2 patients felt a generalized numbness. Two patients described déjà $v u$ phenomena while sexual fantasies were experienced by one patient.

One patient (a 12-year-old boy) had been running out in front of passing cars and was confused and disorientated on admission. Seven patients were agitated and one ran away from the Admissions and Emergency Department, leaving behind his shoes and shirt. Five patients were initially euphoric and of these 4 later became drowsy. Three patients were drowsy but easily rousable when first seen and 2 were uncommunicative and staring blankly.

Two patients exhibited pressure of speech and one was talking to himself. Twelve patients described their experiences as frightening either on admission or after recovery, and 3 had felt that they were going to die.

The principal clinical features are summarized in Table 1.

TABLE 1. Summary of principal clinical features in 27 cases of magic mushroom ingestion

\begin{tabular}{lc}
\hline & No. of patients \\
\cline { 2 - 2 } Perceptual disorder & 23 \\
Mydriasis & 20 \\
Dysphoria & 13 \\
Hyperreflexia & 12 \\
Tachycardia $(\geqslant 100 \mathrm{~b} / \mathrm{min})$ & 10 \\
Drowsiness & 7 \\
Euphoria & 5 \\
\hline
\end{tabular}

\section{Time course}

Twenty patients were entirely recovered after overnight observation, a maximum of $12 \mathrm{hr}$, and indeed, in about $50 \%$ of these patients the entire experience was over within $6 \mathrm{hr}$. Of the other patients: in one the pupils remained dilated at $12 \mathrm{hr}$ (normal at $18 \mathrm{hr}$ ) in one the BP was elevated at $12 \mathrm{hr}$ (normal at $18 \mathrm{hr}$ ) and one was still drowsy at $18 \mathrm{hr}$ (normal at $24 \mathrm{hr}$ ). One patient was still hallucinating $12 \mathrm{hr}$ after admission but not at $24 \mathrm{hr}$.

One patient required admission to a psychiatric unit because of hallucinations in which he identified voices speaking to him as God and the Devil. He was very frightened. The hallucinatory episodes responded rapidly to treatment with chlorpromazine but recurred on 3 successive evenings despite nö further ingestion of mushrooms.

Two patients presented again, one 7 days and on 9 days after the initial episode of mushroom in gestion, both with acute panic attacks and in bot cases after ingestion of considerable quantities alcohol.

\section{Management}

Twenty-four patients were admitted to hospitat for observation, 2 having refused admission an one having been sent home fully recovered. Gastri lavage was performed in 12 patients and 5 were give $\vec{P}$. ipecacuanha. In 4 cases mushrooms were identified if the gastric contents. One patient required adminos istration of chlorpromazine for hallucinations while one patient presenting with a late panic attacks required diazepam.

\section{Discussion}

The practice of magic mushroom ingestion hac been common in the Tayside area in the last $\frac{9}{8}$ Autumns and in a sample of 59 children aged $14-1$. years from 2 school classes, interviewed by A.F.B. approximately $66 \%$ had heard of the propertiesof these fungi. In contrast to the report frorfo Manchester (Hyde et al., 1978) where the useōof magic mushrooms was centered on the "hippy subculture and the report (The Observer, 1980) on group of 'new gypsies' from mid-Wales, the probler in Tayside is clearly different, involving teenager and young adults throughout the social classe Solvent abuse by teenagers has also been a problent in this area.

The important features noted on physical exams ination were mydriasis, hyperreflexia and tachyo cardia of which mydriasis was the most constant feature. Hyde et al., (1978) have commented ow. sympathomimetic effects and in initial volunteep studies (Isbell, 1959; Malitz et al., 1960; Holiste et al., 1960 and Rinkel et al., 1960) utilizing pur8 psilocybin, mydriasis and facilitation of reflexes were prominent features while changes in pulse rate and BP were less constant, with one observes (Malitz et al., 1960) noting that tachycardia an hypertension occurred only in association wit/
anxiety.

A range of psychological responses has bee $\mathbb{C}$ noted in this study. Changes in mood ranged frorto euphoria to severe anxiety and agitation, while variety of perceptual abnormalities occurred. Hado lucinations were on occasion complex and elaborate $\Phi$ by secondary delusions while one patient suffered af hallucinosis which persisted for 3 days. This varietyo of effects has been noted previously (Hyde et al $\frac{0}{\bar{\delta}}$ 
1978). A similar range of response to pure psilocybin when administered to volunteers has also been noted (Isbell, 1959; Malitz et al., 1960; Holister et al., 1960; Rinkel et al., 1960; Parashos, 1976-7) and identical doses of psilocybin may have widely differing effects in different individuals. It has been suggested that the effect on mood in particular is dependent on the subject's pre-exposure personality traits (Parashos, 1976-7).

Treatment by gastric lavage or induced emesis was instituted in 17 patients in this study, the importance of this having previously been emphasized (Lincoff and Mitchell, 1977). The present experience suggests that in the context of the typical clinical features described above and if a good description of the mushrooms ingested is available, as was the case in 21 of the 27 patients, then these procedures are unnecessary.

Amanita muscaria and $A$. pantherina may cause hallucinations or delirium coming on within $2 \mathrm{hr}$ of ingestion (Matthew and Lawson, 1979) and thus the clinical features may be confused with those of psilocybin mushroom ingestion, particularly if there are prominent anti-cholinergic effects. The appearance of these 2 species is very different from the small psilocybin mushrooms (Watling, 1973b), they may be considerably more toxic and if there is any suspicion that they have been ingested then gastric lavage is essential (Matthew and Lawson, 1979).

The authors feel that patients with prominent symptoms should be observed, and particularly agitated patients may benefit from the administration of a benzodiazepine (Solursch, 1976). One patient in the present study required the administration of chlorpromazine for control of hallucinations. Of the 2 patients who presented with attacks of panic some time after the initial episode of mushroom ingestion, one required diazepam and this has been widely used in the management of these so-called 'flashbacks' and attacks of panic associated with abuse of other hallucinogens (Ungeleider and Frank, 1976).

In conclusion, 27 patients presented to hospital emergency departments in Tayside following the ingestion of magic mushrooms. The effects were usually short-lived and the main risks to health appear to be from the acute effects on the patients' behaviour which may be life-threatening. The possibility of ingestion of more toxic species of fungi must also be considered.

\section{Acknowledgments}

We thank Mr Peter Christopher, B.Sc. HND for valuable help in identification of fungi and Dr Ian Clark for criticism of the manuscript. We also thank the members of the consultant staff who gave permission to report on patients under their care and Mrs Lynn Connolly for secretarial help.

\section{References}

Benedict, R.G., Tyler, V.E. \& Watling, R. (1967) Blueing in Conocybe, Psilocybe and a Stropharia species and the detection of psilocybin. Lloydia, 30, 150.

Cooles, P. (1980) Abuse of the mushroom Panaeolus foenisecii. British Medical Journal, 1, 446.

CoOPER, R. (1979) A Guide to British Psilocybin Mushrooms. Revised Edition. Hassle Free Press, London.

HofmanN, A., Heim, R., Brack, A. \& Kobel, H. (1958) Psilocybin ein psychotroper Wirkstoff aus dem moscikanischen Rauschpilz Psilocybe mexicana Heim. Experientia, 14, 107.

Holister, L.E., Prusmack, J.J., Paulsen, J.A. \& RosenQUIST, N. (1960) Comparison of three psychotropic drugs (psilocybin, JB-329, and IT-290) in volunteer subjects. Journal of Nervous and Mental Diseases, 131, 428.

Hyde, C., Glancy, G., Omerod, P., Hall, D. \& Taylor, G.S. (1978) Abuse of indigenous psilocybin mushrooms: a new fashion and some psychiatric complications. British Journal of Psychiatry, 132, 602.

IsBeLL, H. (1959) Comparison of the reactions induced by psilocybin and LSD-25 in man. Psychopharmacologia, 1, 29.

Lincoff, G. \& Mitchel, D.H. (1977) In: Toxic and Hallucinogenic Mushroom Poisoning (Ed by Williams, W.K.), p. 196. Van Nostrand Reinhold Company, New York.

Malitz, S., Eseconer, H., Wilkins, B. \& HoCH, P.H. (1960) Some observations on psilocybin, a new hallucinogen in volunteer subjects. Comprehensive Psychiatry, 1, 8.

Mantle, P.G. \& Waight, E.S. (1969) Occurrence of psilocybin in the sporophores of Psilocybe semilanceata. Transactions of the British Mycological Society, 53, 302.

MatThew, H. \& LAwsON, A.A.H. (1979) Treatment of Common Acute Poisonings. 4th edn, p. 191. Churchill Livingstone, Edinburgh.

Mills, P.R., Lesinkas, D. \& Watkinson, G. (1979) The danger of hallucinogenic mushrooms. Scottish Medical Journal, 24, 316.

Parashos, A.J. (1976-7) The psilocybin-induced 'state of drunkenness' in normal volunteers and schizophrenics. Behavioural Neuropsychiatry, 8, 83.

Pollock, S.H. (1975) The psilocybin mushroom pandemic. Journal of Psychedelic Drugs, 7, 73.

Release Collective (1979) Hallucinogenic Mushrooms. Release Publications Limited, London.

Rinkel, M., Atwell, C.R., Di Mascio, A. \& Brown, J. (1960) Experimental psychiatry V-psilocybin a new psychotogenic drug. New England Journal of Medicine, 262, 295.

Solursch, L.P. (1976) In: Acute Drug Abuse Emergencies (Ed by Bourne, P. G.), p. 139. Academic Press, New York.

The ObServer (1980) Sunday 14th September.

Ungeleider, J.T. \& Frank, I.M. (1976) In: Acute Drug Abuse Emergencies (Ed by Bourne, P. G.), p. 133. Academic Press, New York.

WASson, R.G. (1959) The hallucinogenic mushrooms of Mexico: an adventure in ethnomycological exploration. Transactions of the New York Academy of Sciences, 21, 325.

WAtLing, R. (1973a) Identification of the Larger Fungi, p. 114. Hulton Educational Publications, Amersham.

WAtLING, R. (1973b) Identification of the Larger Fungi, p. 54. Hulton Educational Publications, Amersham. 